\title{
Microstructure of Zr-alloyed coating using pulsed laser
}

\author{
X.L. Wu*, Y.S. Hong \\ State Key Laboratory of Nonlinear Mechanics, Institute of Mechanics, Chinese Academy of Sciences, Beijing 100080, PR China
}

Received 8 March 2000; accepted 6 July 2000

\begin{abstract}
Coatings were synthesized by laser alloying of zirconium (Zr) particles using a pulsed Nd:YAG laser on an austenite stainless steel. The distribution of $\mathrm{Zr}$ is uneven, in a depth of $18 \mu \mathrm{m}$ just below the surface of the pool. The coating consisted of duplex microstructures, i.e. metallic glass (MG) and austenite. The MG formed in $\mathrm{Zr}$-contained regions, with the $\mathrm{Zr}$ composition ranging from 7.6 to 16.8 at.\%. The formation of the MG was attributed to an increase in glass-forming ability by $\mathrm{Zr}$ addition. ( $) 2000$ Elsevier Science S.A. All rights reserved.
\end{abstract}

Keywords: Laser irradiation; Microstructure; Metallic glass

\section{Introduction}

Rickerby and Matthews [1] proposed that surface engineering aims at designing a composite system, i.e. coating plus substrate, which has a performance which cannot be achieved by either the coating or the substrate alone. Laser surface alloying was a most promising technique, because it could obtain the desired composition and microstructure, thus providing remarkable improvements in surface hardness, and fatigue, wear, or corrosion resistance of materials without impairing their bulk properties.

The austenitic stainless steel is widely used owing to its high corrosion resistance. Various particulate-reinforced composite coatings are synthesized on the stainless steel to enhance their relatively low hardness and wear resistance by laser surface alloying [2,3]. However, the microstructural change for enhancing wear resistance adversely injured corrosion resistance [4]. The composite coating led to galvanic corrosion both at the interface between the particulate and the binder alloy and at the bond area between coating and the sub-

\footnotetext{
* Corresponding author. Fax: + 86-10-6256-1284.

E-mail address: xlwu@cc.imech.ac.cn (X.L. Wu).
}

strate. The metallic glass (MG) has high mechanical hardness and superior corrosion resistance. The MGreinforced microstructure can effectively improve both the wear and corrosion resistance. This paper studies the microstructure of the coating obtained by laser alloying of zirconium on an austenitic stainless steel.

\section{Experimental}

The substrate was an austenitic stainless steel, its composition was (wt.\%): $0.06 \mathrm{C}, 18.95 \mathrm{Cr}, 8.85 \mathrm{Ni}, 0.82$ Ti, $0.028 \mathrm{P}, 0.023 \mathrm{~S}$, balance Fe. The sample, with the dimension of $60 \mathrm{~mm} \times 40 \mathrm{~mm} \times 30 \mathrm{~mm}$, was austenized at $1373 \mathrm{~K}$ for $2 \mathrm{~h}$ and then cooled by water. Zirconium $(\mathrm{Zr})$ powders were pre-coated on the substrate surface, with $220 \mathrm{~nm}$ thickness. Powders had a size of approximately $6 \mathrm{~nm}$ and purity of 99.995 wt.\%. A pulse $\mathrm{Nd}$ :YAG laser was used with the full width at half maximum of the near-Gaussian intensity profile. Processing parameters were as follows: beam spot size of $200 \mu \mathrm{m}$, pulse duration of $180 \mathrm{~ns}$, an average output power of $250 \mathrm{~W}$, and a frequency of $12 \mathrm{kHz}$. To prevent oxidation, an inert gas shield was arranged by blowing a 
stream of argon over the irradiated specimen during laser melting.

The microstructure was analyzed using optical microscopy, scanning electron microscopy (SEM), transmission electron microscopy (TEM), and high-resolution transmission electron microscopy (HR-TEM). The chemical composition was determined using an energy-dispersive X-ray analysis (EDX) in conjunction with SEM and TEM, respectively. Thin TEM slices were prepared as follows. The first step was to cut a bar ( $3 \mathrm{~mm}$ in diameter and $30 \mathrm{~mm}$ in length) from the irradiated sample. The long axis was taken normal to the laser-exposed surface. Several thin films of $5 \mu \mathrm{m}$ thickness were successively cut using a diamond knife normal to the long axis of the bar. Such a technique assured observation of the microstructure at a wellidentified depth of the pool. Thin films were subsequently ion milled and perforated.

\section{Results}

\subsection{Morphology of rapid solidification}

Fig. 1a,b shows the optical morphology of the crosssection view and top view of the pool, respectively. The maximum depth of the pool is approximately $60 \mu \mathrm{m}$. The microstructure consists of dendrites of austenite. Fig. 1b shows the refinement of dendrites.

Fig. 2 shows the distribution of $\mathrm{Zr}$ in the pool by EDX. The Zr-alloyed region forms only in the depth of $18 \mu \mathrm{m}$ below the surface. Also, the composition of $\mathrm{Zr}$ is uneven. This is because pulsed laser has a super short effect period. The convection exists only in the top part of the pool and full diffusion of alloyed elements cannot be realized.

\subsection{Microstructure}

Fig. 3 is the bright-field TEM image in the $\mathrm{Zr}$ -

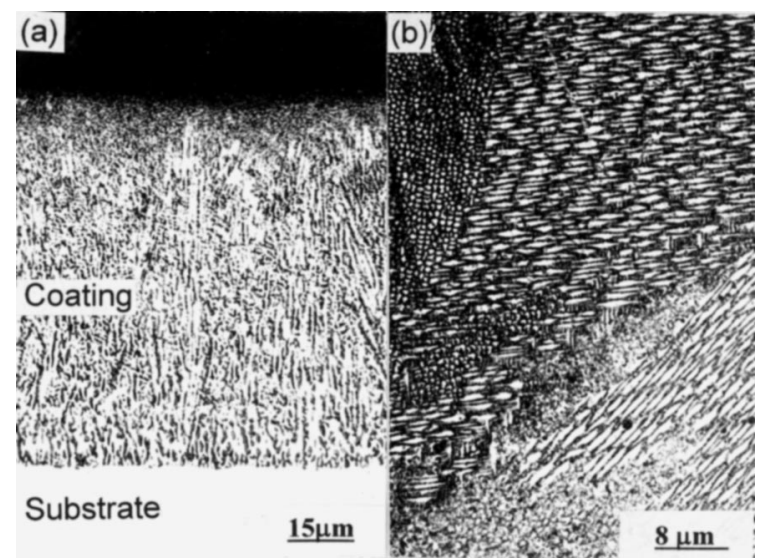

Fig. 1. Optical morphologies of the pool: (a) cross-section view; (b) top view in the interior region of the pool.

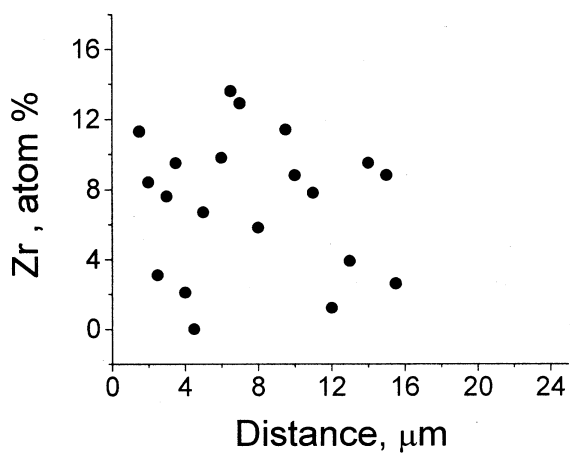

Fig. 2. Distribution of $\mathrm{Zr}$ by SEM/EDX.

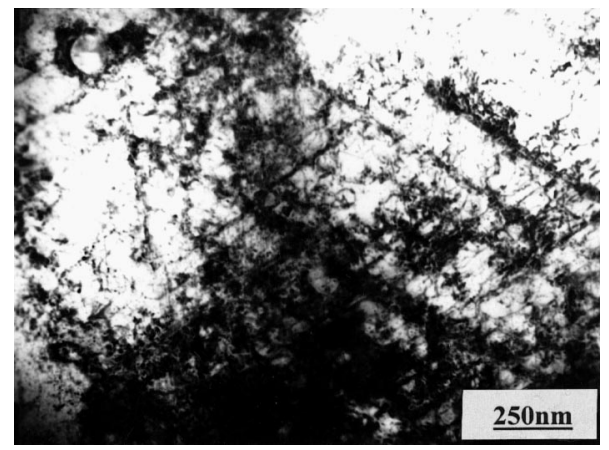

Fig. 3. TEM image showing the austenite microstructure.

alloyed zone. A high density of dislocations and twins exists in the austenitic.

Fig. 4 is a bright-field TEM image showing the MG in the $\mathrm{Zr}$-alloyed zone. The MG of a structureless contrast forms near the austenite dendrite. The selected area diffraction pattern (SADP) shows a broad diffuse halo. The ring has a nearest neighbor distance of the order of $0.203 \mathrm{~nm}$, typical of an iron-based MG. Fig. 5 is the HR-TEM image showing the coexistence of both MG and austenite. EDX analysis indicates that the $\mathrm{Zr}$ composition of the $\mathrm{MG}$ is 8.3 at.\% at $\mathrm{N}$, higher than 4.6 at.\% of austenite at A. TEM observation reveals that the MG has a scattered distribution and

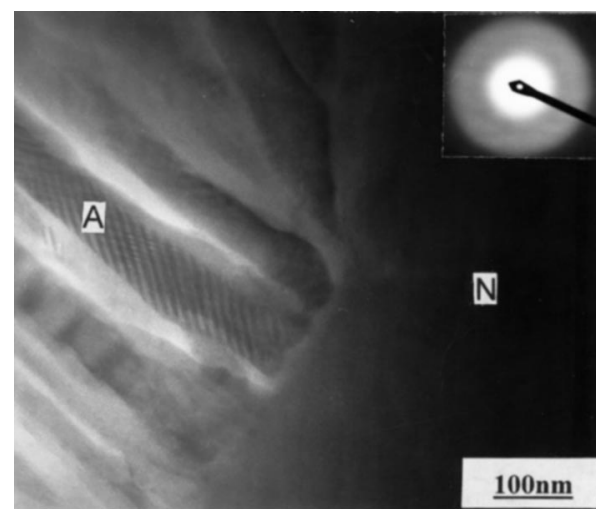

Fig. 4. TEM images showing the coexistence of the MG and austenite (N: MG, A: austenite). 


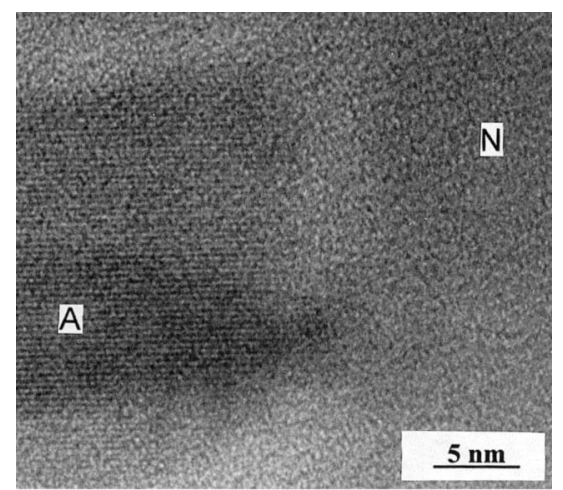

Fig. 5. HR-TEM image showing the coexistence of the $M G$ and austenite (N: MG, A: austenite).

forms only in the $\mathrm{Zr}$-alloyed zone. Therefore, the coating is a dual-phase microstructure, consisting of the MG and austenite.

Table 1 lists the chemical composition of the MG and the nearby austenite by EDX. It is seen that the $\mathrm{Zr}$ content of the MG is higher than that of austenite. $\mathrm{Zr}$ composition of the MG ranges from 7.6 to 16.8 at.\%, similar to that of the Fe-Zr-Ni MG [5].

Novel bulk MGs were discovered recently in $\mathrm{Zr}$-, Mg-, La-, Pd-, Ti-, and Fe-based alloys [6,7]. Distinct from the conventional MG, the bulk MG had multicomponent chemistry and excellent glass formation ability (GFA). For obtaining bulk MG with large GFA, Inoue [6] proposed the following three empirical rules, namely: (i) a multi-component system consisting of more than three constituent elements; (ii) significantly different atomic size ratios above approximately $12 \%$ among the main constituent elements; and (iii) large negative heats of mixing the main constituent elements. Inoue et al. [8-10] developed a series of Fe-based Zr-contained bulk MGs.

The reason for the formation of MG in the present investigation can be discussed in the framework of the above empirical rules. The present MG is a multicomponent system, as can be seen from Table 1. The atomic size of the main constituent elements decreases systematically in the order of $\mathrm{Zr}(0.158 \mathrm{~nm})>\mathrm{Cr}(0.128$ $\mathrm{nm})>\mathrm{Ni}(0.125 \mathrm{~nm})>\mathrm{Fe}(0.124 \mathrm{~nm})$ and significantly different atomic size ratios among $\mathrm{Zr} / \mathrm{Fe}, \mathrm{Zr} / \mathrm{Ni}$, and $\mathrm{Zr} / \mathrm{Cr}$ exist. Meanwhile, there exist large negative heats of mixing among the above constituent elements, as is evidenced from the predicted negative enthalpies of

Table 1

Chemical composition by EDX (at.\%)

\begin{tabular}{llllll}
\hline & $\mathrm{Zr}$ & $\mathrm{Fe}$ & $\mathrm{Cr}$ & $\mathrm{Ni}$ & $\mathrm{Ti}$ \\
\hline $\begin{array}{c}\text { Amorphous } \\
\text { phase }\end{array}$ & 10.3 & 69.4 & 12.6 & 6.8 & 0.9 \\
$\begin{array}{c}\text { Austenite } \\
\text { matrix }\end{array}$ & 3.6 & 70.8 & 16.8 & 8.2 & 0.6 \\
\hline
\end{tabular}

mixing of $37-72 \mathrm{~kJ} / \mathrm{mol}$ for $\mathrm{Fe}-\mathrm{Zr}$, Ni-Zr and $\mathrm{Cr}-\mathrm{Zr}$ pairs [8]. Therefore, constituent elements have large negative heats of mixing and large atomic size ratios because of the addition of $\mathrm{Zr}$. Resulting from the significant atomic size differences, the multicomponent MG has random closer packing structure than that of the conventional MG [6,7]. This kind of microstructure suppresses nucleation and growth of the crystalline phase in the supercooled liquid state by inhibiting the long distance diffusion and increasing the melting viscosity and leads to a large increase in GFA [6,7]. Therefore, the formation of the MG in the Zr-alloyed region was attributed to an increase in GFA by $\mathrm{Zr}$ addition.

Two processes also favor the formation of the MG. First, the high solute enrichment in the Zr-enriched region may supply a high degree of undercooling of the liquid. Depending on the nature of the interface rearrangements, the rate of the heat removal can be much faster than the interface kinetics, so that the undercooling at the interface is large, and metastable phases can be formed. This corresponds to interface-limited growth [11]. Secondly, a high cooling rate is achieved at the very surface of the pool because of the liquid-atmosphere heat exchange. This means that under the short-pulsed laser condition, no long-range diffusion can occur and the only possible transformations are partitionless ones, either growth of a crystal of the same composition of the liquid, or MG formation.

\subsection{Hardness}

Fig. 6 shows the hardness of the layer. The hardness increases from 1.8 to $2.1 \mathrm{GPa}$ of the substrate to 3.8-4.6 GPa in MG-contained regions of the pool. This is attributed mainly to the formation of the MG, the refinement of the microstructure and a high density of dislocations and twins.

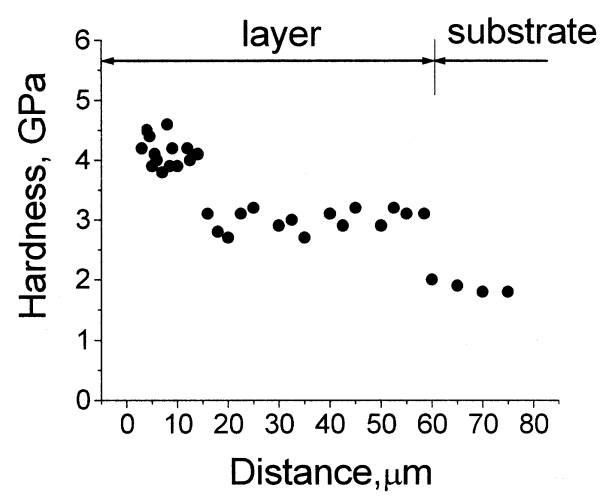

Fig. 6. Distribution of hardness as function of the pool depth. 


\section{Conclusions}

Laser surface alloying of $\mathrm{Zr}$ powders produced a coating of duplex microstructures consisting of MG and austenite using a pulsed Nd:YAG laser. The MG forms in $\mathrm{Zr}$-alloyed regions with $\mathrm{Zr}$ content ranging from 7.6 to 16.8 at.\%. The addition of $\mathrm{Zr}$ causes an increase of glass-forming ability and the formation of the MG.

\section{Acknowledgements}

This research was supported by National Natural Science Foundation (Grant No. 1989 1180), National Outstanding Youth Scientific Award of China and The Chinese Academy of Sciences (Grant No. KJ951-1-201).

\section{References}

[1] D.S. Rickerby, A. Matthews, Introduction, in: D.S. Rickerby, A.
Matthews (Eds.), Advanced Surface Coatings: a Handbook of Surface Engineering, Blackie, Glasgow, 1991, pp. 1-13.

[2] T.H. Kim, B.C. Kim, J. Mater. Sci. 27 (1992) 2967.

[3] F. Laroudie, C. Tassin, M. Pons, J. Mater. Sci. 30 (1995) 3652.

[4] K.P. Kooper, P.L. Slebodnick, K.E. Lucas, E.A. Hogan, J. Mater. Sci. 33 (1998) 3805.

[5] A. Inoue, H. Tomioka, T. Masumoto, J. Mater. Sci. 16 (1981) 1935.

[6] A. Inoue, Mater. Trans. JIM 36 (1995) 866.

[7] W.L. Johnson, Mater. Sci. Forum 35 (1996) 225.

[8] A. Inoue, T. Zhang, T. Itoi, A. Takeuchi, Mater. Trans. JIM 38 (1997) 359.

[9] A. Inoue, T. Zhang, A. Takeuchi, Appl. Phys. Lett. 7 (1997) 464.

[10] A. Inoue, H. Koshiba, T. Zhang, A. Makino, J. Appl. Phys. 83 (1998) 1967.

[11] F. Spaepen, in: E.W. Collings, C.C. Koch (Eds.), Undercooled Alloy Phases, TMS-AIME, New York, 1987, p. 187. 